\title{
Analysis of gene polymorphic variants of angiotensinconverting enzyme, glutathione S-transferase in cardiomyopathy sick patients
}

\author{
Arvid R. Berg, A.N. Chepurnaya, D.O. Karimov, T.V. Viktorova, V.I. Nikulicheva, G.Sh. Safuanova \\ Bashkirian State Medical University, Ufa, Russia
}

Accepted 15 October 2012

Original Text in Russian (c) Berg AR, Chepurnaya A N, Karimov DO, Viktorova TV, Nikulicheva VI, Safuanova GSh, 2012, published in Saratov Journal of Medical Scientific Research 2012; 8(2): 224-228.

\begin{abstract}
Cardiomyopathies (CMP) are considered diseases with unknown etiology. CMP are usually diagnosed on the late stages of the disease. It is an important task to seek methods which allow diagnosing CMP on the early stages of development. Aim - to estimate the type of polymorphic variants of angiotensin converting enzyme (ACE), glutathione S-transferase (GSTM1) frequency distribution among the CMP sick and healthy individuals living in the Republic of Bashkortostan, and to substantiate their role in the CMP pathogenesis. Material and Methods - There were 67 CMP sick put under observation. Out of them 40 werediagnosed ischemic cardiomyopathy (ICM), and 27 were diagnosed dilated cardiomyopathy (DCM). The control group was made up of 110 practically healthy people. The results. In the ICM sick group the DD genotype $\left(\chi^{2}=4.8 ; p=0.029\right)$ was definitely found more frequently, also in case of $D C M$ the increase of $D D$ genotype $\left(\chi^{2}=4.0, p=0.044\right)$ frequency was ascertained. Conclusion - The genetic analysis of polymorphic locus of I/D ACE gene in the ICM and DCM sick showed decrease in frequency of occurrence II, ID genotypes, I allele and increase of D genotype and D allele which points out the increased risk of these cardiovascular diseases.
\end{abstract}

Keywords: cardiomyopathies, polymorphic variants, angiotensin converting enzyme, glutathione S-transferase.

Cite as Berg AR, Chepurnaya A N, Karimov DO, Viktorova TV, Nikulicheva VI, Safuanova GS. Analysis of gene polymorphic variants of angiotensinconverting enzyme, glutathione S-transferase in cardiomyopathy sick patients. Russian Open Medical Journal 2012; 1: 0301.

Correspondence to Arvid R. Berg. Address: a/ya 92, Ufa, 450104, Russia. E-mail: anzor@ufanet.ru

\section{Introduction}

Cardiomyopathies (CMP) are still considered as diseases with unknown etiology. The effect of inotropic agents, disturbance of adrenoreceptors' structure and functions, change of intercellular substance's structure were considered as possible reasons [1]. The pathogenesis of multifactorial diseases is complicated and implies that participation of many pathogenesis sections. There are several reasons of diffuse myocardium changes formation defined: immune and autoimmune affection, energy and hemodynamic disorders [2].

In case of dilated CMP (DCM) the main one is systolic heart insufficiency which is characterized by a significant reduction of stroke volume because of dramatic ejection fraction decrease, increase of terminal systolic and diastolic volume of the left ventricle and increase of diastolic pressure in it.

In all forms of CMP, the significant changes of heart are found, although they are not specific. Myocytolysis, Anitschkow myocyteeosinophilia, lymphohysteocytic infiltrates of subacute and chronic type can be identified morphologically, though the infiltration doesn't have significant differences of its character from the myocarditis' one [2, 4].

Identification of the genes which lead to CMP development is one of the main tasks of modern molecular-genetic cardiology and may subsequently result in creation of the new methods of CMP treatment and diagnosis.

There were several mutations discovered in the heavy chains genes of $\beta$-myosin, titin, dystrophin, desmin and lamin which lead to CMP development $[5,6]$. However, it is considered undoubted that in spite of many described genes, responsible for the CMP development, the majority of them remains unexplored and cardiomyopathies are considered to be illnesses with unknown etiology and bad forecast [1]. At the present time the hypothesis that the defect of the genes disturbing myocardium contraction power generation lead to GCMP and the defects disturbing myocardium contraction power transition lead to DCM received the highest recognition. In connection with that further analysis of effect and impact of genes modifiers on CMP etiology and pathogenesis is considered actual [7].

It is undoubted that the CMP pathogenesis is to a large degree connected with renin-angiotensin system. During the influence of various pathogenetic factors, affecting the myocardium, the reninangiotensin system stays in a state of hyperactivity and is used for cardiovascular homeostasis maintenance. Successful counteraction to the damaging factors requires timely regulation of heart vessels resistance which is necessary for adequate blood circulation maintenance. This process depends to a large extent on activation of renin-angiotensin system, vasodilativeprostaglandins as well as bradykinin, endothelin II, nitrogen oxide by the vessels endothelium. Theangiotensin converting enzyme (ACE) is a zinc metallopeptidase which catalyzes conversion of angiotensin I into vasoconstrictive peptide - angiotensin II and bradykinin breakdown into inactive peptides simultaneously. Bradykinin is one of the stimulants of endothelium discharge of nitrogen oxide which is the main factor of endothelial relaxation. So, ACE is the key link in maintenance of equilibrium between vasoconstriction 
and vasodilation factors $[8,9]$. The ACE gene is localized in the long arm of chromosome 17 (17q23). According to National Center for Biotechnology Information (NCBI), there are more than 160 polymorphic variants described in the ACE gene, most of which are mononucleotide substitutes. The insertion and deletion polymorphism of the $16^{\text {th }}$ gene intron which is evident byexistence or absence of $278^{\text {th }}$ pair of bases (I/D) is being widely studied now [9].

There is evidence that the genetic variants of genes glutathione redox system enzymes may be a factor of predisposition for cardiovascular system diseases, where the leading role is played by the heart tissues damaged because of pollutant and oxidant effect [10]. Such changes are mainly connected with pathology in the toxic substances, free radicals and other heart damaging factors neutralization system. Glutathione (GSH) which can be found in all mammals' tissues plays important role in organism antioxidant protection. The main glutathione's antioxidant effect is fulfilled by its participation in the enzymatic antioxidants work; being GPX1 and GST substrate glutathione is an atom donor for hydrogen peroxide and lipidic peroxides. Also, glutathione is active oxygen forms inhibitor and cellular membrane stabilizer [10]. The mu $(\mu)$-class glutathione $\mathrm{S}$ transferase gene (GSTM1) is localized in the $1 \mathrm{p} 13$ section and is represented by five genetic locuses GSTM1, GSTM2, GSTM3, GSTM4 and GSTM5. The GSTM1 gene is highly expressing itself in the liver and the heart as well. The GSTM1 locus has 3 allelic forms: the afunctional zero allele (10000 p.n. deletion), and 2 GSTM1*A and GSTM1*B alleles which are differed by a couple of nucleotides in the $7^{\text {th }}$ exon. It was proved that the zero allele of the GSTM1 gene had appeared as a result of unequal crossing over.

CMP is usually diagnosed on the later stage of development when the most of myocardium changes become irreversible, because of that it is an important task to find diagnostic criteria which allow diagnosing CMP on the earlier stages of development. The analysis of ACE and GSTM1 genes polymorphic variants is timely and topical.

The aim: to estimate the ACE and GSTM1 polymorphic variants frequency distribution among the CMP sick and the healthy individuals living in the Republic ofBashkortostan and prove their role in CMP pathogenesis.

\section{Material and Methods}

There were $67 \mathrm{CMP}$ sick put under observation. In case of 40 of them ischemic cardiomyopathy (ICM) was diagnosed, and 27 were diagnosed dilated cardiomyopathy (DCM); the mean age was $62.12 \pm 4.32$ years. The control group was made up of 110 practically healthy people, citizens of the Republic ofBashkortostancomparable with the CMP sick in terms of age, gender and ethnicity, without chronic diseases as well as without pathology of cardiovascular system in the anamnesis.

The patients were included after they signed up the informed consent. The research was approved by Bashkirian State Medical University ethical committee. The inclusion criteria: the DCM and ICM sick patients, who had their pathologies, diagnosed in compliance with $\mathrm{WHO}$ classification criteria, $\mathrm{EF}<45 \%$, agreed to take part in the research. The exclusion criteria were: the aortic regurgitation and stenosis sick, the patients with the prosthetic valves, implanted heart pacemakers, the patients with heavy exocardial somatic pathology. The DCM and ICM diagnosis was verified on the basis of clinical data, as well as clinic instrumental research, including ECG, echocardiogram, and coronarography.

The results of central and intracardiac hemodynamics rates analysis indicates hemodynamics hypokinetic character in case of DCM and ICM sick patients, more evident in DCM (Table 1) [3].

All patients were carried out a coronarography. In DCM there were no hemodynamicly significant coronary artery stenoses. In ICM there were stenosing affections of three coronary arteries at the same time in case of 24 patients (as well as the common trunk of the left coronary artery of two patients), the affection of two coronary arteries were diagnosed of 16 patients (as well as the front interventricular artery and right coronary artery of 9 patients, the front interventricular artery and circumflex artery of 5 patients, the right coronary artery and circumflex artery of two patients).

The DNA samples that were extracted from the peripheric venous blood lymphocytes of examined individuals by the usage of phenolic-chloroform extractionwere the material for the molecular-genetic analysis [12]. The examination of the polymorphic locuses was carried out by the DNA synthesispolymerase chain reaction (PCR). The list of the locuses examined, locus-specific oligonucleotide primers sequencies, the ways of polymorphisms' detection, as well as alleles' nomenclature were taken from literary sources $[8,10,13,14]$. Credibility ofdifferences of frequency distribution of the alleles and genotypes among the groupsand association with clinical illness course was revealed by comparison of the samples using the $\chi^{2}$ criterion with Yates' correction with help of BIOSTAT program. The differences of $p<0.05$ were considered statistically important. The relative risk of a disease for a certain factor was computed as chances ratio, the computation was carried out in program name Statistica v 6.0.

\section{Results}

The polymorphic I/D ACE, del GSTM1 locuses genotypes frequency distribution among the groups of ICM and DCM sick and the control group corresponded to the expected one according to Hardy-Weinberg equilibrium.

During the comparison of the general sample of the ICM sick group and the control group the significant differences in polymorphic I/D ACE gene locus frequencies were revealed (Table 2). In the ICM sick group the DD genotype was encountered more frequently in comparison with the control group $28.9 \%$ and $11.0 \%$ respectively, $\left.\chi^{2}=4.8, p=0.029\right)$. It was noted that increase of $D$ allele frequency $\left(\chi^{2}=3.7, p=0.055\right)$, but the level of significant differences was not achieved. The research showed that in case of ICM the tendency of decrease in II ACE gene $\left(\chi^{2}=0.8, p=0.387\right)$, ID $\left(\chi^{2}=0.4, p=0.543\right)$, I allele $\left(\chi^{2}=3.7, p=0.055\right)$ polymorphic variants frequency is noted. Also, the statistical analysis showed that in case of ICM decrease of polymorphic locus GSTM1 del genotype occurred $\left(\chi^{2}=1.7, p=0.188\right)$, although it did not reach the level of significant differences what we attribute to the small sample number.

In case of DCM the increase in ACE gene polymorphic locus $\left(\chi^{2}=4.0, p=0.044\right), D$ allele $\left(\chi^{2}=1.4, p=0.235\right)$, on the contrary the decrease of genotype II frequency $\left(\chi^{2}=0.002, p=0.966\right)$, ID genotype $\left(x^{2}=1.7, p=0.200\right)$, I allele $\left(\chi^{2}=1.4, p=0.235\right)$ DD genotype frequency was ascertained. In case of DCM the increase in del genotype frequency of GSTM1 $\left(\chi^{2}=0.020, p=0.899\right)$ gene polymorphic locus was ascertained; however the significant differences level was not achieved (Table 3). 
Table 1. Indices of intracardiac hemodynamics of dilated and ischemic cardiomyopathy sick patient [3]

\begin{tabular}{|c|c|c|c|}
\hline Indices & Control & DCM & ICM \\
\hline $\mathrm{EDV}, \mathrm{ml}$ & $88.46 \pm 0.24$ & $188.7 \pm 19.2 * * *$ & $123.4 \pm 8.98 * * *$ \\
\hline $\mathrm{ESV}, \mathrm{ml}$ & $29.26 \pm 0.22$ & $140.4 \pm 14.7^{* * *}$ & $58.05 \pm 6.65 * * *$ \\
\hline $\mathrm{EDD}, \mathrm{ml}$ & $43.02 \pm 0.20$ & $62.95 \pm 1.92 * * *$ & $50.04 \pm 1.66 * * *$ \\
\hline $\mathrm{ESD}, \mathrm{ml}$ & $31 \pm 0.01$ & $47.16 \pm 2.32 * * *$ & $34.5 \pm 1.54 *$ \\
\hline$E F, \%$ & $69.40 \pm 1.001$ & $38.68 \pm 2.77 * * *$ & $46.49 \pm 2.32 * * *$ \\
\hline $\mathrm{AS}, \mathrm{mm}$ & $30.01 \pm 1.10$ & $45.2 \pm 1.51 * * *$ & $38.51 \pm 1.50 * * *$ \\
\hline $\mathrm{AD}, \mathrm{mm}$ & $35.0 \pm 0.03$ & $44.17 \pm 1.32 * * *$ & $39.78 \pm 1.04 * * *$ \\
\hline IVS, mm & $8.01 \pm 0.04$ & $8.95 \pm 0.30 * *$ & $10.26 \pm 1.40 * * *$ \\
\hline LVPW, mm & $10.16 \pm 0.14$ & $9.56 \pm 0.28 *$ & $10.26 \pm 0.40 *$ \\
\hline
\end{tabular}

The reliability of difference relative to the healthy is designated that way: ${ }^{*}-p<0.05 ; * *-p<0.01 ;^{* * *}-p<0.001$

Table 2. The allele and genotypes distribution in the ICM sick group and the control group

\begin{tabular}{|c|c|c|c|c|c|c|c|c|c|}
\hline \multirow{2}{*}{ Polymorphic locus } & \multirow{2}{*}{ Genotypes } & \multicolumn{2}{|c|}{ ICM sick } & \multicolumn{2}{|c|}{ Control group } & \multirow{2}{*}{$x^{2}$} & \multirow{2}{*}{$\mathrm{p}$} & \multirow{2}{*}{ OR } & \multirow{2}{*}{$\mathrm{Cl}-95 \%$} \\
\hline & & a & $\mathrm{f}$ & a & $\mathrm{f}$ & & & & \\
\hline \multirow[t]{6}{*}{ I/D ACE } & $\mathrm{N}$ & 38 & & 82 & & & & & \\
\hline & II & 11 & 0.289 & 32 & 0.390 & 0.750 & 0.387 & 0.637 & $0.278-1.461$ \\
\hline & ID & 16 & 0.421 & 41 & 0.500 & 0.371 & 0.543 & 0.728 & $0.335-1.581$ \\
\hline & DD & 11 & 0.289 & 9 & 0.110 & 4.814 & 0.029 & 3.305 & $1.234-8.854$ \\
\hline & 1 & 38 & 0.500 & 105 & 0.640 & 3.679 & 0.055 & 0.562 & $0.324-0.976$ \\
\hline & D & 38 & 0.500 & 59 & 0.360 & 3.679 & 0.055 & 1.780 & $1.026-3.089$ \\
\hline \multirow[t]{3}{*}{ del GSTM1 } & $\mathrm{N}$ & 40 & & 110 & & & & & \\
\hline & Normal & 28 & 0.700 & 62 & 0.564 & 1.740 & 0.188 & 1.807 & 0.833-3.919 \\
\hline & del & 12 & 0.300 & 48 & 0.436 & 1.740 & 0.188 & 0.554 & $0.255-1.202$ \\
\hline
\end{tabular}

$\mathrm{N}$ is the sample size. The cells with a reliable level of significance $(\mathrm{p}<0.05)$ are typed in bold. $a-$ is the absolute value (number of people), $f-$ is frequency.

Table 3. Distribution of alleles and genes genotypes in DCM sick patients group and in control group

\begin{tabular}{|c|c|c|c|c|c|c|c|c|c|}
\hline \multirow[b]{2}{*}{ Polymorphic locus } & \multirow[b]{2}{*}{ Genotypes } & \multicolumn{2}{|c|}{ DCM sick } & \multicolumn{2}{|c|}{ Control group } & \multirow{2}{*}{$x^{2}$} & \multirow[b]{2}{*}{$\mathrm{p}$} & \multirow[b]{2}{*}{ OR } & \multirow[b]{2}{*}{$\mathrm{Cl}-95 \%$} \\
\hline & & a & $f$ & a & $\mathrm{f}$ & & & & \\
\hline \multirow[t]{6}{*}{ I/D ACE } & $\mathrm{N}$ & 27 & & 82 & & & & & \\
\hline & II & 10 & 0.370 & 32 & 0.390 & 0.002 & 0.966 & 0.920 & $0.375-2.258$ \\
\hline & ID & 9 & 0.333 & 41 & 0.500 & 1.651 & 0.200 & 0.501 & $0.202-1.243$ \\
\hline & DD & 8 & 0.296 & 9 & 0.110 & 4.046 & 0.044 & 3.416 & $1.162-10.037$ \\
\hline & I & 38 & 0.537 & 105 & 0.640 & 1.417 & 0.235 & 0.652 & $0.35-1.216$ \\
\hline & D & 38 & 0.463 & 59 & 0.360 & 1.417 & 0.235 & 1.535 & $0.823-2.861$ \\
\hline \multirow[t]{3}{*}{ Del GSTM 1} & $\mathrm{~N}$ & 27 & & 110 & & & & & \\
\hline & Normal & 15 & 0.556 & 62 & 0.564 & 0.020 & 0.899 & 0.968 & $0.415-2.260$ \\
\hline & del & 12 & 0.444 & 48 & 0.436 & 0.020 & 0.899 & 1.034 & $0.443-2.431$ \\
\hline
\end{tabular}

$\mathrm{N}$ is the sample value. The cells with a reliable level of significance $(\mathrm{p}<0.05)$ are typed in bold. $\mathrm{a}-$ is the absolute value (number of people), $\mathrm{f}-$ is frequency.

\section{Discussion}

As the result of the research, there was shown maintenance of a tendency in the ACE gene polymorphic locus frequency distribution (both towards a decrease in II genotype, ID genotype and I allele frequency and towards an increase of DD genotype and allele $D$ frequency) in the ICM and DCM sick groups, which can be an evidence of the common pathomorphological mechanism of these diseases. On the basis of the available literary sources, the increased level of the ACE geneassociated with D allele, apparently leads to cardiovascular system adaptive capabilities deterioration, on one hand and prevents adequate decrease of the vessels' resistance - on the other one, which leads to the development of myocardium disorders. This can explain the association of ACE with CMP we have shown. Besides, the polymorphism in the intron 16 examined by us can be in the state of unbalanced linkage with some other polymorphic variant in the ACE gene, which can directly influence the protein structure and gene expression level [15]. It is considered, that I and D allele of the ACE gene are, apparently, codominant. As a result, the level of enzyme in the alternative genotype carriers blood plasma is increasing in the sequence: $I I \rightarrow I D \rightarrow D D$. This fact explains at least half of observed interindividual differences. Despite of fact that this polymorphism is being widely studied during the various cardiovascular and other complex diseases, its localization in the noncoding region does not imply the presence of a certain functional enzyme variant. However in the research conducted there were no any significant polymorphisms found.At the same time, in different populations certain ACE gene haplotypes form clydes and, just as the majority of candidate region polymorphisms, are in a state of strong disequilibrium with by linkage with insertion-deletion polymorphism. Because of that, the I/D polymorphism is still being used as an easy-to-use marker studying associations between the unknown functional polymorphisms and pathophysiological conditions [15].

\section{Conclusion}

The ACE gene I/D polymorphic locus analysis showed statistically significant increase in DD genotype frequency of ICM sick, which indicates of cardiovascular system genetic predilection for ICM development of atherosclerosis and CHD sick patients and can be used for ICM development risk prediction.

The DCM sick were revealed to have a statistically significant increase of ACE gene I/D polymorphic locus DD genotype which demonstrates disposition to multiple-factor cardiovascular system injuries development for this contingent of patients and can be used for DCMP development risk prediction. 
Conflict of interest: This work was performed as a doctoral thesis.

\section{Reference}

1. Shliakhto EV, Gudkova AY, Kostareva AA, et al. Primary cardiomyopathies: current view. Ter Arkh 2005; (12): 77-83 (PMID: 16514827) [Article in Russian].

2. Amosova EN, Rahmatullina AR, Berg AR. Cardiomyopathies. Kniga plus Publ., Kiev, Ukraine, 1999 [Text in Russian].

3. Chepurnaya AN. Clinical-instrumental comparison in case of dilated and ishemic cardiomyopathy. Hurghada international scientific conference material 2009: 402-407 [Text in Russian].

4. Gurevich MA, Sisakian AS. Pathogenesis and treatment of cardiac failure in dilated cardiomyopathy. Klinicheskaia meditsina 2001; (10): 4-8 [Article in Russian].

5. Frisso G, Sampaolo S, Pastore L, Carlomagno A, Calise RM, Di lorio G, Salvatore $F$. Novel deletion at the $M$ and $P$ promoters of humendystrophin gene associated with Duchenne muscular dystrophy. Neuromuscular Disorders 2002; 12: 494-497 (PMID: 12031623).

6. Arbustini E, Pilotto A, Repetto A, Grasso M, Negri A, Diegoli M, et al. Autosomal dominant dilated cardiomyopathy with atrioventricular block: a lamin A/C defect-related disease. Journal of the American College of Cardiology 2002; 39: 981-990 (PMID: 11897440) (doi: 10.1016/S0735-1097(02)01724-2).

7. Olson TM, Kishimoto NY, Whitby FG, Michels VV. Mutations that alter the surface charge of alpha - tropomyosin are associated with dilated cardiomyopathy. Journal of Molecular and Cellular Cardiology 2001; 33: 723-732 (PMID: 11273725) (doi: 10.1006/jmcc.2000.1339).

8. Ashavaid TF, Shalia KK, Nair KG, Dalal JJ. ACE and AT1R gene polymorphisms and hypertension in Indian population. Journal of Clinical and Laboratory Analysis 2000; 14: 230-237 (PMID: 11018802) (doi: 10.1002/1098-2825(2000)14:5<230::AID-JCLA6>3.0.CO;2-U).

9. Tiret L, Rigat B, Visvikis S., Breda C, Corvol P, Cambien F, Soubrier F. Evidence from combined segregation analysis that a variant of the angiotensin l-converting enzyme (ACE) gene controls plasma ACE levels. American journal of human genetics 1992; 51: 197-205 (PMID: 1319114).

10. Baranov VS, Ivaschenko T, Bakay B, Aseev M, Belotserkovskaya R, Baranova $\mathrm{H}$, et al. Proportion of the GSTM1 0/0 genotype in some Slavic populations and its correlation with cystic fibrosis and multifactorial diseases. Human Genetics 1996; 97: 516-520 (PMID: 8834254).

11. Gonlugur $U$, Pinarbasi H, Gonlugur TE, Silig Y. The Association between polymorphisms in Glutathione S-Transferase (GSTM1 and GSTT1) and lung cancer outcome. Cancer Investigation 2006; 24: 497-501 (PMID: 16939958).

12. Mathew CG. The isolation of high molecular weight eucariotic DNA. In: Methods in Molecular Biology: ed. J.M. Walker. Human Press, NY, USA, 1984; Vol. 2: 31-32.

13. Hull J, Ackerman H, Isles K, Usen S, Pinder M, Thomson A, Kwiatkowski D. Unusual haplotypic structure of IL8, a susceptibility locus for a common respiratory virus. American Journal of Human Genetics 2001; 69: 413-419 (PMID: 11431705) (PMCID: PMC1235312) (doi: 10.1086/321291).

14. Kaluza W, Leirisalo-Repo $M$, Märker-Hermann E, Westman $P$, Reuss $E$, Hug R, et al. IL10 microsatellites mark promoter haplotypes associated with protection against the development of reactive arthritis in Finnish patients. Arthritis Rheum 2001; 44: 1209-1214 (PMID: 11352256) (doi: 10.1002/1529-0131(200105)44:5<1209::AID-ANR205>3.0.CO;2-S).

15. Hattori MA, Del Ben GL, Carmona AK, Casarini DE. Angiotensin Iconverting enzyme isoforms (high and low weight) in urine of premature and full-term infants. Hypertension 2000; 35: 1284-1290 (PMID: 10856278) (doi: 10.1161/01.HYP.35.6.1284).

Authors:

Artur R. Berg - MD, Post-graduate, Department of Therapy and General Medical Practice with Course of Geriatrics, Bashkirian State Medical
University, Ufa, Russia;

A.N. Chepurnaya - MD, PhD, Assistant Professor, Department of Therapy and General Medical Practice with Course of Geriatrics, Bashkirian State Medical University, Ufa, Russia;

D.O. Karimov - Assistant, Department of Biology, Bashkirian State Medical University, Ufa, Russia;

T.V. Viktorova - MD, D.Sc., Professor, Head of Department of Biology, Bashkirian State Medical University, Ufa, Russia;

V.I. Nikulicheva - MD, D.Sc., Professor, Head of Department of Therapy and General Medical Practice with Course of Geriatrics, Bashkirian State Medical University, Ufa, Russia;

G.Sh. Safuanova - MD, D.Sc., Professor, Department of Therapy and General Medical Practice with Course of Geriatrics, Bashkirian State Medical University, Ufa, Russia. 